\title{
Une fiction qui mérite de nous inspirer dans la vraie vie
}

\section{Jean Martin}

Dr méd., membre de la rédaction

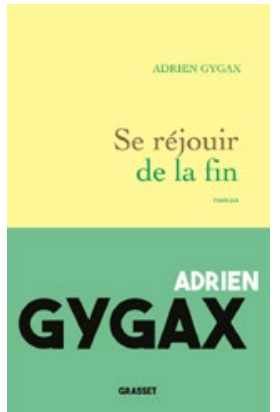

Adrien Gygax Se réjouir de la fin

Paris: Grasset; 2020 106 pages
Né en 1989, Adrien Gygax est un écrivain suisse. Il signe ici son deuxième roman, imaginé suite à son activité de consultant dans un EMS de Lausanne. Cette fiction se présente comme un écrit prétendument trouvé dans les affaires d'un résident décédé. Sur la base de ses contacts avec des personnes âgées, l'auteur vaudois a voulu proposer des alternatives au jeunisme ambiant et aux injonctions vis-à-vis des seniors (rester actif, dépasser ses limites). Il a approfondi sa réflexion en compagnie de Sénèque, Cicéron et Lucrèce: «Je voulais voir si c'était jouable d'être hédoniste à 90 ans. Trouver un peu de beauté dans le déclin.»

Adrien Gygax nous offre un récit attachant, plein de sagesse et léger: le narrateur est un nonagénaire veuf depuis peu. Il parle de sa chère épouse Nathalie sans lamentations, acceptant qu'elle ne soit plus là bien que son décès ait causé l'entrée en EMS; plutôt, il se réjouit de ce qui a été vécu ensemble.

Ces bouleversements l'amènent à passer en revue sa vie et à évoquer le temps qui défile: «’ai vécu les poings serrés, n'ai rien voulu lâcher [...] Le temps m'a appris le contraire. On prévoit, on construit sur un tas de sable que le vent de la vie déforme à son gré.» "J'aimais ma maison et détestais les maisons de retraite. Pourtant me voilà dans ce bloc de béton [...] Mais j'arrête le

L'auteur a voulu proposer des alternatives au jeunisme ambiant et aux injonctions vis-à-vis des seniors.

contrôle, la crispation. Si je ne le fais pas maintenant, je ne le ferai jamais. Je vais prendre une grande inspiration, me déplier comme une fleur au soleil.»

Le vieux résident réfléchit aussi à son lien aux biens matériels, desquels il s'est détaché avec les années: «J'ai possédé bien des choses. J'étais ce grand type en Mercedes [...] Le temps passe et avec lui certaines de nos libertés, comme le droit de conduire... Vient alors le temps du don, une pluie nécessaire après la sécheresse de la possession. Le don est une libération. Je n'ai plus rien, le monde est riche pour moi." «Je me sens loin de tout, de moins en moins concerné [...] je peux me dire de gauche comme de droite, macho ou fé- ministe, tout me va. Ces catégories sont les vôtres. Seuls m'intéressent maintenant la couleur du ciel, celles des fleurs, l'envol d'un oiseau. Le plus grandiose est le silence.» D'autres des vingt-cinq courts chapitres parlent des repas, de l'endormissement, de la visite du docteur, de voyager avec la musique et de l'amour: «En premier quand on est jeune - on aime devant soi. Puis l'amour dure, s'alourdit, s'offre une mémoire. Alors on aime toujours devant soi mais aussi derrière.»

«Ma vie n'en peut plus de s'étirer. Elle est lourde de toutes ces joies et s'enfonce doucement dans le sol.»

Est aussi abordée la question de la transmission: «On transmet malgré soi, malgré tout. Ce sont les autres qui décident de la part de nous qui est transmise, ils nous cambriolent en douceur [...] On ne sait jamais ce qu'on transmet vraiment, ce n'est pas une chose qui se voit dans un miroir."

Dans une maison de retraite, la mort fait partie du quotidien: «Tout ça a pris fin avec la mort de Pierre. On ne le voyait plus et le 'journal club' était annulé. C'est lui qui nous maintenait dans le mouvement [...] Ils ont installé des ordinateurs dans le salon.» "Avec quelques autres on s'est rendu à la cérémonie en son honneur. Cela nous occupe bien, et on y trouve quelquefois de bonnes idées pour la nôtre.»

Et puis il y a la fin de sa propre vie, qui approche à mesure que l'on s'affaiblit: «Ils m'ont trouvé une chaise roulante. On s'accroche parfois trop à l'idée qu'on a de la normalité, comme s'il n'existait aucune autre façon de vivre que celle des valides [...] Avec ma chaise roulante, je vais où mes pieds ne me portaient plus.»

A la dernière page, le résident conclut: "Ma vie n'en peut plus de s'étirer. Elle est lourde de toutes ces joies et s'enfonce doucement dans le sol [...] Je me réjouis de voir ma vie se terminer comme j’ai dû me réjouir de la voir commencer.»

"Oui, c'est la grande question", répond Adrien Gygax quand on lui demande si une dernière partie de vie, comme celle qu'il décrit, rassérénée, tranquille, pleine d'une bonne philosophie, est possible. 